Rev. Interd. em Cult. e Soc. (RICS), São Luís, v. 7, n. 1, p. 148 - 168, jan./jun. 2021

\title{
Suplementos alimentares e musculação: uma análise sociocultural ${ }^{1}$
}

\section{Dietary supplements and resistance training: a socio-cultural analysis}

\author{
ALAN CAMARGO SILVA \\ Doutor em Saúde Coletiva (UFRJ). Pós-Doutor em Educação Física (UFRJ) \\ Professor das redes Municipal e Estadual de Educação do Rio de Janeiro \\ Professor do curso de pós-graduação lato sensu EEFD/UFRJ e do CESPEB (UFRJ) \\ alan10@zipmail.com.br
}

TADEU JOÃO RIBEIRO BAPTISTA Doutor em Educação (UFG). Pós-Doutor em Educação (UNICAMP) Professor do Departamento de Educação Física da UFRN tadeujrbaptista@yahoo.com.br

MARIA ISABEL BRANDÃO DE SOUZA MENDES Doutora em Educação (UFRN). Pós-Doutora (Universidade de Montpellier - França) Professora do Programa de Pós-Graduação em Educação Física da UFRN isabelbsm1@gmail.com

SÍLVIA MARIA AGATTI LÜDORF Doutora em Educação (UFRJ). Pós-Doutorado no Instituto de Medicina Social (UERJ) Professora do Programa de Pós-Graduação em Educação Física da EEFD/UFRJ silvialudorf@eefd.ufrj.br

\section{RESUMO}

Este estudo analisou como os consumidores de suplementos alimentares gerenciam esses produtos em suas rotinas, identificando especialmente o que ou como privilegiam a busca de informações acerca dessas substâncias. Foram aplicados questionários no ambiente Facebook a 67 praticantes de atividades físicas de academias de ginástica, além de observações nos grupos dessa rede social. Com base na análise de conteúdo temática, foi possível compreender como os usuários de suplementos alimentares lidam com os produtos. Esses achados podem instrumentalizar criticamente os campos da Educação Física e da Saúde no que diz respeito à intervenção profissional, à comercialização ou ao consumo da população e à elaboração de políticas públicas sobre o tema.

Palavras-chave: Saúde. Corpo. Educação Física. Suplementos Alimentares. Musculação.

\section{ABSTRACT}

This study looked at how consumers of dietary supplements manage these products in their routines, especially identifying what or how they favour the search for information about these substances. Questionnaires were applied in the Facebook environment to 67 gyms' physical activities practitioners, in addition to observations in the groups of this social network. Based on thematic content analysis it was possible to understand how users of dietary supplements manage the products. These findings can critically instrumentalize the Physical Education and Health fields with regard to

\footnotetext{
${ }^{1}$ Artigo submetido em 03/11/2020 e aprovado em 10/02/2021.
} 
Rev. Interd. em Cult. e Soc. (RICS), São Luís, v. 7, n. 1, p. 148 - 168, jan./jun. 2021 ISSN eletrônico: 2447-6498

professional intervention, to the marketing or consume of the population and to the elaboration of public policies on the subject.

Keywords: Health. Body. Physical Education. Dietary Supplements. Resistance Training.

\section{CONSIDERAÇÕES INICIAIS}

Nos últimos anos, parece ter se intensificado o interesse por estudos socioculturais sobre as academias de ginástica (MACHADO; FRAGA, 2017; CORREIA; GOMES, 2018; SILVA; FREITAS; LÜDORF, 2019). Entretanto, um dos recursos mais utilizados pelos frequentadores para cultuar ou cuidar do corpo mereceria atenção: o uso de suplementos alimentares. Há poucos trabalhos específicos sobre este tema presentes na interface entre os campos da Educação Física e da Saúde, abordando as implicações físico-orgânicas dos produtos em relação às lógicas simbólicas dos usuários com base nas suas inserções sociais, culturais e econômicas (SABINO; LUZ; CARVALHO, 2010; SILVA, 2017).

Nessa direção, este trabalho foi inspirado e fundamentado pelo referencial teórico da Sociologia do Corpo (SHILLING, 2007; LE BRETON, 2016), mais especificamente com base nos pressupostos da Antropologia da Alimentação (APPADURAI, 1988; MINTZ, 2001). A premissa pressupõe que alimentar-se não é apenas um “comportamento natural” individual, mas é também permeado por lógicas culturais passíveis de análise em função de cada grupo social e tempo histórico (CASTRO; MACIEL, 2013; KLOTZ-SILVA; PRADO; SEIXAS, 2017).

Assim, pode-se compreender que "tomar suplementos alimentares" e seus consumos ou consumismos também se constituem como uma construção sociocultural em diferentes grupos e faixas etárias (KUWAE et al., 2015; JUZWIAK, 2016). Nesse sentido, o presente trabalho se orienta a partir das seguintes questões: como os praticantes de atividade física lidam com os suplementos alimentares nas academias ao longo do tempo? Como os sujeitos conhecem esses produtos e de que forma os manejam em seu dia a dia com as práticas corporais? Ou ainda, quais são os principais elementos que levam os frequentadores de academia a tomar os suplementos alimentares de determinado modo e de que maneiras costumam incorporar esses produtos em seu cotidiano?

Destarte, pode-se destacar a relevância deste estudo pautado nos seguintes argumentos: primeiramente, para além dos efeitos físico-orgânicos dessas substâncias (THOMAS; ERDMAN; BURKE, 2016), é importante conhecer os sentidos e significados associados ao seu consumo e suas eventuais repercussões para as práticas corporais, para melhor instrumentalizar a intervenção de profissionais da Educação Física e da Saúde em 
Rev. Interd. em Cult. e Soc. (RICS), São Luís, v. 7, n. 1, p. 148 - 168, jan./jun. 2021 ISSN eletrônico: 2447-6498

geral. No que diz respeito a esses produtos, Silva (2017) afirma a necessidade de humanizar a atuação profissional que entende o outro como protagonista da intervenção. Em segundo lugar, possibilita questionar ou fazer pensar criticamente a comercialização e o consumo desses tipos de produto em tempos de redes sociais e de aumento do marketing da cultura fitness (STOLARSKI et al., 2018). Para Vasconcellos-Silva et al. (2010), ocorrem modificações identitárias daqueles que se tornam reféns do autocuidado ou do culto ao corpo em prol de uma "saúde idealizada", sobretudo, a partir das novas tecnologias da informação.

Acrescenta-se ainda que esta pesquisa pode colaborar para ampliar ponderações ou mesmo subsidiar proposições em relação a direções reflexivas para elaboração de políticas públicas de vigilância sanitária, de campanhas educativas e de regulamentação desses produtos com base nas concepções dos próprios consumidores de suplementos alimentares, considerando o fato de, nos últimos anos, ter ocorrido um aumento significativo da preocupação governamental e dos debates sobre o processo de inspeção dessas substâncias (STARR, 2016; KERKSICK et al., 2018). Collaço e Menasche (2015) destacam criticamente a inegável produção, diversificação, expansão e circulação de mercadorias alimentícias atualmente.

Assim, o objetivo deste trabalho foi analisar como os consumidores de suplementos alimentares gerenciam esses produtos em suas rotinas, identificando especialmente o que ou como privilegiam a busca de informações acerca dessas substâncias.

\section{PROCEDIMENTOS METODOLÓGICOS}

Privilegiou-se, neste estudo qualitativo, o ponto de vista dos praticantes de musculação que fizessem uso de suplementos alimentares. Para a composição do universo empírico, adotaram-se os seguintes critérios para a seleção dos pesquisados: estar, no mínimo, com 18 anos de idade; ser praticante, pelo menos, do setor da musculação na academia; e ter experienciado a rotina de consumir suplementos alimentares. Optou-se, em especial, pela musculação por ser vista como um espaço onde os frequentadores competem por "modelos de corpo", o que pode gerar um sentimento do sujeito de inadequação ao espaço das academias (SILVA, 2017). Este delineamento metodológico atende ao aprofundamento da compreensão de um grupo social com base na diversidade de pontos de vista dos pesquisados (GOLDENBERG, 2011).

Durante três meses no ano de 2016, para a geração do material empírico, foram utilizados questionários e observações. As diferentes estratégias de construção dos dados 
Rev. Interd. em Cult. e Soc. (RICS), São Luís, v. 7, n. 1, p. 148 - 168, jan./jun. 2021

ISSN eletrônico: 2447-6498

constituem o processo de triangulação, a fim de potencializar as possibilidades de compreensão do objeto de estudo (GOLDENBERG, 2011).

Utilizou-se, a princípio, somente a aplicação de questionários com perguntas “abertas" na rede social Facebook, um dos primeiros espaços virtuais desse tipo, que reúnem pessoas, mais representativos do mundo (LEWIS et al., 2008). Divulgou-se o link (URL) do questionário em domínio próprio na web (“com.br") em todos os 120 grupos brasileiros existentes na época sobre atividades físicas, nutrição e suplementos alimentares. O tempo médio de duração para responder ao questionário era de aproximadamente dez minutos.

O questionário continha três partes: uma, referente ao perfil do participante, incluindo dados sobre sexo, idade, local de moradia, categoria socioprofissional, rendimentos, tempo de prática da musculação e frequência semanal desta prática. A outra parte consistia em buscar detalhes sobre os suplementos alimentares utilizados e suas experiências com a musculação, desde a rotina sobre o uso de suplementos, locais e horários de ingesta, fonte em que se baseia para determinar a dosagem, até o custo financeiro mensal com os suplementos. Na última parte do questionário, havia questões "abertas" sobre o surgimento do interesse de usar suplementos e quem o influenciou, sobre possíveis mudanças após começar a ingerir suplementos, sobre a continuidade do uso, maneira de escolher o produto consumido, tipos de produtos utilizados, onde se buscam informações sobre o que está sendo ingerido e se conhece possíveis malefícios ou riscos para o organismo devido ao uso de suplementos. Estas questões abertas permitiram "respostas livres de juízo de valor" pela privacidade e anonimato sem o contato face a face com o pesquisador, além da maior disponibilidade de tempo. Segundo Lüdorf (2017), o ambiente virtual tem sido utilizado por facilitar o acesso e a divulgação da pesquisa.

Ressalta-se que, para garantir o rigor e a validade deste instrumento, o questionário passou por "testagem" antes da aplicação oficial, mais precisamente por um estudo piloto e pelo processo de validação (VARANDA; BENITES; SOUZA NETO, 2019).

No entanto, a fim de dirimir, em parte, algumas desvantagens da aplicação dos questionários (GOLDENBERG, 2011), detectadas no trabalho de campo como a obtenção de "respostas curtas", ao longo das primeiras buscas dos grupos da rede social Facebook, emergiu a necessidade de também realizar observações nesses espaços. Assim, utilizou-se um diário de campo no qual foram feitas anotações sistemáticas sobre o funcionamento dessas comunidades virtuais: foram observadas desde as postagens e trocas de mensagens entre os participantes dos 120 grupos, como eram construídos em termos de regras, imagens e 
Rev. Interd. em Cult. e Soc. (RICS), São Luís, v. 7, n. 1, p. 148 - 168, jan./jun. 2021 ISSN eletrônico: 2447-6498

administração, o que foi fundamental para compor a compreensão sobre as concepções sobre quem consome os suplementos alimentares.

Investigações qualitativas no campo da cibercultura possibilitam adentrar nas lógicas simbólicas daqueles que circulam nesses tipos de espaços virtuais (SEGATA; RIFIOTIS, 2016) e a exploração da vivência dos internautas pode indicar em que medida esses espaços se constituem em um universo de potenciais riscos pelo compartilhamento de informações de forma rápida e de fácil acesso (GARBIN; GUILAM; PEREIRA NETO, 2012).

Foram respondidos 174 questionários, no entanto houve a seleção de 67 sujeitos que atenderam a todos os critérios supracitados: 38 homens e 29 mulheres, sendo 55 residentes do estado do Rio de Janeiro. Os outros 12 residem nos seguintes estados: São Paulo, Minas Gerais, Goiás, Ceará, Bahia, Alagoas, Paraíba e Rondônia. Embora se destaque o número de moradores do Rio de Janeiro, pode-se considerar a representatividade dessa cidade vista como a capital do culto ao corpo e do número elevado de academias (MALYSSE, 2007). A faixa etária dos pesquisados concentrou-se entre 18 a 40 anos de idade, profissões ou ocupações laborais variadas (arquiteto, advogado, analista de sistema, vendedor, dentista, bancário, engenheiro, militar, professor, jornalista, eletricista, operador de máquinas, bilheteiro, cabeleireiro, comerciário, enfermeiro, etc.) e ganhavam entre R \$ 1.450,00 a R\$ 14.499,99 (nove pesquisados ganhavam até dois salários mínimos, 15 entre dois a quatro, 20 entre quatro a 10, 15 entre 10 a 20 e 2 acima de 20 salários mínimos, três não informaram a renda e três alegaram não ter renda). Ressalta-se que grande parte do grupo realizava a musculação entre duas a três vezes ou entre quatro a cinco vezes na semana e tinha envolvimento com a prática há três anos ou mais. Interrompeu-se o acréscimo de novos informantes por saturação teórica, ou seja, quando a captação de novos sujeitos gerou certa redundância ou repetição dos dados (TURATO, 2011).

Os dados foram tratados a partir da análise de conteúdo temática proposta por Turato (2011) em que se privilegia a identificação e a interpretação de expressões textuais mais recorrentes e as mais relevantes no corpus, considerando-se o objetivo da investigação.

Esta pesquisa foi autorizada pelo Comitê de Ética em Pesquisa do Hospital Universitário Clementino Fraga Filho vinculado à Universidade Federal do Rio de Janeiro, sob o seguinte registro: CAAE: 52465115.7.0000.5257 / Número do parecer: 1.426.698.

\section{APRESENTAÇÃO E DISCUSSÃO DOS ACHADOS}

A partir da análise dos dados, criaram-se três eixos de discussão. O primeiro e o segundo abordam, respectivamente, como os usuários escolhem e manipulam os suplementos 
Rev. Interd. em Cult. e Soc. (RICS), São Luís, v. 7, n. 1, p. 148 - 168, jan./jun. 2021 ISSN eletrônico: 2447-6498

alimentares. No terceiro, explora-se as formas relacionadas a como aprendem sobre os produtos. Cada eixo é iniciado por um Quadro, com uma visão geral dos achados.

\subsection{Escolhendo os produtos...}

Quadro 1 - Critérios para escolha dos produtos

\begin{tabular}{|c|c|}
\hline $\begin{array}{c}\text { Critérios para escolha dos } \\
\text { produtos }\end{array}$ & Exemplos de respostas \\
\hline Marca & $\begin{array}{l}\text { - } \quad \text { Marca, matéria prima. } \\
\text { - } \quad \text { Marca reconhecida e de boa qualidade. } \\
\text { - } \quad \text { Credibilidade da marca e sua concentração. } \\
\text { - } \quad \text { Saber se é confiável, a marca e o produto. } \\
\end{array}$ \\
\hline Custo versus benefício & $\begin{array}{l}\text { - A qualidade e o preço. } \\
\text { - Possuir laudo comprovando quantidade proteica e não } \\
\text { ser demasiadamente caro. } \\
\text { - Que seja fácil de obter, de preparar e não tenha sabor } \\
\text { ruim, além de caber no orçamento. }\end{array}$ \\
\hline Riscos evitados & $\begin{array}{l}\text { - Como estou com } 31 \text { anos, prefiro os suplementos que } \\
\text { forneçam suporte às articulações e aos produtos pré- } \\
\text { hormonais e anabolizantes. } \\
\text { - Avaliação risco versus benefício. } \\
\text { - Confiabilidade. } \\
\text { - Não pratico tanto musculação hoje em dia! Pratico } \\
\text { lutas, procuro produtos já conhecidos e que não tenham } \\
\text { efeitos colaterais em meu organismo. }\end{array}$ \\
\hline Eficácia científica & $\begin{array}{l}\text { - Que seja auxiliador e que melhore meu desempenho e } \\
\text { resultados. } \\
\text { - Resultado provado por estudos de que realmente ajuda. } \\
\text { - A real comprovação científica de que tal produto } \\
\text { atende aos meus objetivos de ganho de força e } \\
\text { hipertrofia muscular e o tempo (tradição) em que tal } \\
\text { produto vem sendo utilizado com benefícios reais por } \\
\text { atletas e praticantes sérios do universo do } \\
\text { halterofilismo/fisiculturismo. }\end{array}$ \\
\hline
\end{tabular}

Fonte: Dados originais da pesquisa

No Quadro 1, são apresentados os principais motivos para a escolha dos produtos. Essas "escolhas" devem ser analisadas com base na ideia de que os sujeitos acionam determinados usos do corpo em função das suas condições materiais e simbólicas em dadas circunstâncias econômicas e socioculturais (BOURDIEU, 2001; BOLTANSKI, 2004). Entende-se que "escolher" o que ingerir faz parte das lógicas culturais que enredam o que o sujeito elege como legítimo para si em função das suas inserções sociais.

Assim, a noção de uma marca confiável, de qualidade, reconhecida e com crédito pode contribuir para se evitar os riscos do uso dos suplementos alimentares e, muitas vezes, 
Rev. Interd. em Cult. e Soc. (RICS), São Luís, v. 7, n. 1, p. 148 - 168, jan./jun. 2021 ISSN eletrônico: 2447-6498

está relacionada à pretensa eficácia científica conforme identificam as trocas de informações e pesquisas sobre os produtos. Logo, algumas empresas vinculadas a estas substâncias acabam sendo responsáveis diretas pela opção de certo suplemento alimentar pelos usuários. Isso pode ocorrer pela possibilidade de estas empresas terem maiores estratégias de marketing e recursos para divulgação. As postagens de opiniões acerca das "marcas" se misturavam entre as dezenas de propagandas de produtos publicados pelos membros dos grupos.

Assim, a depender do potencial de mercado da marca, há significativas influências das propagandas desses produtos no universo dos usuários de suplementos alimentares. Com efeito, as marcas sugerem que não basta "alimentar-se para treinar", já que as publicidades induzem os consumidores a entenderem que "sempre estão em falta com algo" para alcançar determinada forma corporal. Pode-se ver nas redes sociais que as marcas se aproveitam das imagens do cotidiano e de treinos das chamadas "musas fitness", objetivando argumentar que a suplementação é inerente no dia a dia do praticante de academia (VENTURINI et al., 2020).

Uma evidência deste fato é apresentada por Sauerbronn, Tonini e Lodi (2011) sobre a relação entre o corpo feminino e marcas de suplementos alimentares. Os pesquisadores detectaram o fato de algumas marcas apostarem na demonstração da ação do produto. Ao se remeterem à análise dos rótulos, os autores notaram o destaque dado ao corpo associado à informação técnica, como uma forma de construir uma relação com o receptor da mensagem sobre a eficiência dos produtos, "potencializando" capacidades, "oxidando gorduras" e associando às informações uma imagem corporal que "confirma" a ação objetiva do produto.

O mercado fitness e todos os produtos associados a esse universo de práticas corporais, como os suplementos alimentares, não param de expandir seus negócios (KERKSICK et al., 2018). Para Vasconcellos-Silva et al. (2010, p. 1474): “Os indivíduos em suas práticas de autocuidado, se submetem a artefatos, prescrições e interdições, regimes de economia calórica e terapias através dos quais conseguem se ver e se identificar, embora, nesse percurso, reduzindo-se a consumidores". Na lógica de uma sociedade do consumo e criação dos consumidores, o marketing busca explorar categorias, com estratégias próprias para cada nicho (SAUERBRONN; TONINI; LODI, 2011).

A preocupação constante com a saúde leva os sujeitos a terem mais "consciência" ou "atenção" com o corpo (LE BRETON, 2011). Os usos de suplementos alimentares demonstram a racionalidade nutricional do que seria "comer bem" em prol de um corpo saudável, demarcando, sobretudo, a construção identitária com base em determinados gostos alimentares (CASTRO; MACIEL, 2013). No entanto, o binômio eficácia-segurança citado pelos participantes não precisa se atrelar só à escolha da "marca" do suplemento alimentar em 
Rev. Interd. em Cult. e Soc. (RICS), São Luís, v. 7, n. 1, p. 148 - 168, jan./jun. 2021 ISSN eletrônico: 2447-6498

relação ao potencial "positivo" do produto. Pode haver um sentido de distinção entre os grupos sociais, uma vez que não somente demonstra um "saber tomar", mas também estabelece uma hierarquia simbólica entre os consumidores (SILVA, 2017). Esta relação simbólica, apesar de todos os cuidados aparentes na escolha, pode gerar falsa sensação de segurança, pois muitas pesquisas possuem conflitos de interesse e são financiadas pelos próprios fabricantes (SOUZA et al., 2013).

É nessa direção que, no ponto de vista dos pesquisados, o foco central para o consumo seria a relação entre custo versus benefício. Os participantes também avaliam os custos dos produtos, um dos fatores responsáveis pela manutenção ou troca de determinado suplemento alimentar, pois, entre outras coisas, ele deve "caber no orçamento". Isso pôde ser visto em diferentes perfis de renda, o que não demonstra necessariamente a relação direta com "ter dinheiro" para conseguir comprar determinado produto, mas também o que se valoriza entre esses usuários e como tais substâncias afetam a dimensão financeira desse grupo social. Esse contexto significa que, além do componente simbólico de tomar este ou aquele produto para se destacar perante o grupo social, as condições objetivas ou materiais "pesam" na escolha do suplemento alimentar.

Os membros dos grupos, comerciantes e usuários, postavam frequentemente os produtos que vendiam associando-os, por vezes, a acessórios como luvas de musculação, roupa sportwear, squeezes, tênis, etc. A escolha de determinados suplementos alimentares junto a outros acessórios contribui para a construção de um estilo de vida pautado no consumo de objetos exibidos pela indústria da beleza e que são reforçados pelas práticas de culto ao corpo (CASTRO, 2007). A cultura do consumo é reforçada por Baudrillard (2011), sendo capaz de ativar determinados signos. Nesta pesquisa, associa-se o uso destes acessórios a uma busca por um corpo esportivizado. Entretanto, ainda que haja essa associação com o esporte, registra-se que tal forma de construção de corpo também se fundamenta no quanto podem pagar ou em que medida o suplemento alimentar pode trazer certos benefícios.

Outro ponto de destaque é que o uso de suplementos alimentares também pode estar ligado à busca pelo direito de gerir o próprio organismo por meio da escolha de tais produtos. Ou seja, o ato de se exercitar, somado à suplementação, parece resumir uma forma adequada de gerenciar o próprio corpo. Refletindo com Bourdieu (2001), nesse lócus específico do "campo fitness", esses usos sociais do corpo estão associados à construção de determinados habitus.

Além da marca e do custo versus benefício, a noção de evitar riscos emerge como uma preocupação. Atualmente, os riscos potencializados pela insegurança alimentar já são 
Rev. Interd. em Cult. e Soc. (RICS), São Luís, v. 7, n. 1, p. 148 - 168, jan./jun. 2021 ISSN eletrônico: 2447-6498

uma realidade cotidiana, sobretudo, pelas mudanças no padrão de consumo alimentar e pela publicidade de estímulo à "suplementação", a qual pode causar riscos à saúde (ABEMATSUMOTO et al., 2015). Estudos demonstraram a gravidade e os impactos corporais negativos devido à ingestão de suplementos alimentares "contaminados" (PARRA; PALMA; PIERUCCI, 2011; CASTANHO; FONTES; FERNANDES, 2014), podendo afetar as atividades pelo balanço nutricional inadequado (MOREIRA; RODRIGUES, 2014).

O "corpo suplementado" dos participantes sempre verifica, examina ou avalia o que está colocando "para dentro de si”. Os discursos normativos, universais e prescritivos da racionalidade científica biomédica sobre o que se denomina de "alimentação saudável" (CASTIEL; FERREIRA; MORAES, 2014) expande-se também para um modo de viver "sem riscos" com o consumo dos suplementos alimentares. Os discursos biomédicos sobre a alimentação desconsideram o contexto social, cultural ou psicológico, preocupando-se apenas com a ingesta de nutrientes com foco biológico (KLOTZ-SILVA; PRADO; SEIXAS, 2017).

Em que pese a preocupação biomédica em ditar o que é benéfico ou maléfico à saúde, torna-se imperioso lembrar que "o risco é uma noção socialmente construída, eminentemente variável de um lugar para outro e de uma época para outra." (LE BRETON, 2009, p. 11). Assim, questiona-se em que medida os sujeitos "se arriscam" em tomar esses produtos, pois a noção de risco é plural, fluida e transitória segundo os grupos sociais. Nesse sentido se propõe um "olhar sociocultural" sobre o corpo, em especial, sobre a alimentação (CASTRO; MACIEL, 2013; KLOTZ-SILVA; PRADO; SEIXAS, 2017).

O elemento de eficácia científica também emergiu das respostas. A representação implícita nessa ideia é de haver um anseio dos consumidores em relação ao alcance dos objetivos, contudo sem efeitos colaterais pelo uso continuado dessas substâncias. Não basta apenas ter "efeitos", também é preciso se cercar da impossibilidade de qualquer "mal-estar" derivado do consumo dos suplementos. Entretanto, vale arguir se o fato de não apresentar efeitos colaterais agudos (imediatos ou de curto prazo) gera segurança ou, por outro lado, significaria que talvez pudessem ser percebidos somente em médio a longo prazo. Hirschbruch, Fisberg e Mochizuki (2008) alertam que não se conhecem a potência e pureza das substâncias nutricionais e, com isso, não há informações sobre os efeitos de longo prazo.

$\mathrm{O}$ receio e a desconfiança sobre esses produtos quanto à eficácia científica são compreensíveis, porquanto os próprios posicionamentos, diretrizes e a própria produção do conhecimento sobre o tema ainda são assaz inconclusivos ou incipientes (THOMAS; ERDMAN; BURKE, 2016; KERKSICK et al., 2018). Tomar suplementos alimentares 
Rev. Interd. em Cult. e Soc. (RICS), São Luís, v. 7, n. 1, p. 148 - 168, jan./jun. 2021

ISSN eletrônico: 2447-6498

depende de fatores como a condução do treinamento, da especificidade ou individualidade quanto à alimentação, componentes ambientais e genéticos (MAUGHAN et al., 2018).

Se as proposições sobre "limiares ideais" ou "doses-resposta" adequadas do impacto da atividade física sobre a saúde ainda são extensamente dúbias, parece que o ajuste com o uso de suplementos alimentares complexifica ou obscurece ainda mais o universo das "evidências científicas". Segundo Le Breton (1999), o corpo fica exposto ou à mercê da ciência para ser endireitado tecnicamente e se transformar em um "objeto ideal".

\subsection{Manipulando os produtos...}

Quadro 2 - Motivos de alterações ou manutenções de determinados produtos

\begin{tabular}{|c|c|}
\hline $\begin{array}{l}\text { Motivos de alterações ou } \\
\text { manutenções de } \\
\text { determinados produtos }\end{array}$ & Exemplos de respostas \\
\hline Orientação profissional & $\begin{array}{l}\text { - Sob orientação da nutricionista, eu mantive os mesmos } \\
\text { suplementos. O que ocorre é que ela me orienta em fazer um } \\
\text { intervalo para alguns destes suplementos. Logo, fico alguns } \\
\text { meses aguardando para o retorno do uso de alguns dos } \\
\text { suplementos. } \\
\text { - Às vezes o médico e a nutricionista pedem pra retirar a } \\
\text { suplementação e aumentar a ingestão de proteínas na } \\
\text { alimentação. } \\
\text { - Já alterei algumas vezes, após avaliações feitas por } \\
\text { nutricionista, nutróloga e endocrinologista. }\end{array}$ \\
\hline Experiências negativas & $\begin{array}{l}\text { - Alterei. Já tomei alguns suplementos e ao longo dos anos fui } \\
\text { trocando por questões de adaptação e alguns parei de usar } \\
\text { pois não me fizeram bem. } \\
\text { - Alterei. Já fiz uso de muitos suplementos alimentares, entre } \\
\text { eles suplementos estimulantes "pré-treino". Com o passar } \\
\text { do tempo, percebi minha dependência destes. Além disso, } \\
\text { há indícios - os importados - que contenham antidepressivos } \\
\text { e similares, o que gerou minha recusa a estes produtos. } \\
\text { - Alterei. Usava um hipercalórico, mas era ruim de tomar } \\
\text { (digerir). Aí comecei a usar whey mais maltodextrina pelas } \\
\text { minhas pesquisas na internet. } \\
\text { - Substituí o hipercalórico, dá muita barriga! }\end{array}$ \\
\hline Novas experiências & $\begin{array}{l}\text { - Antes tinha mais interesse em maior volume muscular, de } \\
\text { modo que tomava outros concomitantemente. } \\
\text { - Às vezes uso diferentes por curiosidade e teste. } \\
\text { - Alterei tendo em vista a mudança de objetivo de treino. } \\
\text { Deixei de apenas ganhar massa passei a melhorar a massa } \\
\text { corporal que adquiri. } \\
\text { - Sempre fiquei no básico da suplementação, experimentei } \\
\text { outros produtos, mas agora fico nos que julgo necessário. }\end{array}$ \\
\hline $\begin{array}{l}\text { Busca de qualidade e preço } \\
\text { dos produtos }\end{array}$ & $\begin{array}{l}\text { - Já mudei de marcas, devido a valores do mercado. } \\
\text { - Alterei principalmente as marcas, priorizando produtos de } \\
\text { qualidade, mesmo com valor mais elevado, quando possível } \\
\text { comprar. } \\
\text { - Foram alterados de acordo com a qualidade dos produtos. } \\
\text { - Às vezes troco sim de fabricantes. Pela questão financeira e }\end{array}$ \\
\hline
\end{tabular}


Rev. Interd. em Cult. e Soc. (RICS), São Luís, v. 7, n. 1, p. 148 - 168, jan./jun. 2021

ISSN eletrônico: 2447-6498

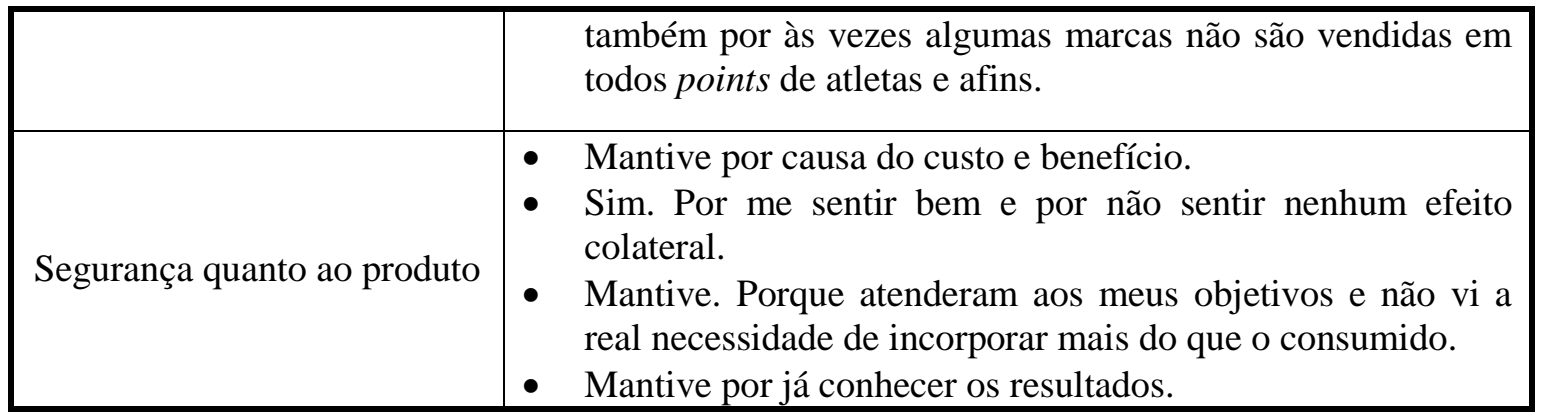

Fonte: Dados originais da pesquisa

No Quadro 2, é possível identificar os principais motivos que levam os participantes da pesquisa a manter ou trocar os produtos. Os pesquisados justificaram sua adesão ao uso dos suplementos alimentares com base na orientação profissional. Este fator é importante, considerando que os profissionais, sobretudo os nutricionistas, possuem o respaldo legal e os conhecimentos adequados para propor o tipo de dieta para cada caso, embora o médico ou o especialista em nutrição esportiva, por vezes, assuma esse papel (SILVA, 2017).

Defende-se que a supervisão de algum profissional de saúde torna-se indispensável para o consumo. Entretanto, sabe-se que essa realidade não significa que a orientação técnicocientífica prescritiva será seguida em totalidade. Helman (1994) lembra que há backgrounds econômicos, culturais e sociais intervenientes na forma de os usuários conceberem as práticas e os saberes em saúde, pois, a todo instante, os ressignificam a partir das suas realidades e experiências. Boltanski (2004) demonstrou que os usos sociais e percepções do corpo, alimentos e medicamentos variam entre camadas sociais. Analogamente, pode-se afirmar que o consumo de suplementos alimentares atrela-se não somente às condições financeiras, como também aos aspectos simbólicos conforme a posição social do sujeito em relação à sua renda.

Foi possível notar que a manipulação dos produtos também se estabeleceu a partir de experiências negativas ou até de novas experiências, embora aqui não se descarte em que medida as orientações profissionais podem ter influência ou tensionar os usos do corpo dos praticantes. Por um lado, estão as experiências negativas com os produtos devido, por exemplo, a efeitos colaterais ou por promoverem dependência. De outro lado, há as possíveis "novidades do mercado", ou as necessidades de alterar o produto de acordo com mudanças de treino ou objetivos de cada praticante. Por vezes, os ditos "novos produtos" podem não apresentar diferenças significativas quando comparados aos outros já existentes no mercado.

Nota-se que a experiência durante a utilização de suplementos alimentares é fundamental para o processo de continuidade ou não do uso de certos produtos, dado esse que pode ser confirmado pela relativa familiariaridade dos pesquisados com a musculação e, por 
Rev. Interd. em Cult. e Soc. (RICS), São Luís, v. 7, n. 1, p. 148 - 168, jan./jun. 2021 ISSN eletrônico: 2447-6498

consequência, pelos próprios (des)usos ou abusos de certas substâncias. Ademais, a depender do treinamento adotado e dos objetivos do sujeito, o consumo do produto pode variar entre os praticantes. Embora isso não apareça nos dados do presente estudo, Silva (2017) apontou indícios de que havia justamente formas diferentes de manipulação dos produtos a depender das classificações êmicas entre os praticantes mais experientes, avançados ou veteranos e iniciantes ou novatos. Independentemente desse dado, para Hirschbruch; Fisberg e Mochizuki (2008), o consumo de suplementos alimentares é considerado uma prática comum da realidade específica das academias, favorecendo o uso de determinados produtos.

Ressalta-se que os suplementos alimentares podem representar o aprofundamento do processo de industrialização alimentar. Sabino, Luz e Carvalho (2010) destacam que há a troca do "cultivo do paladar" por uma rápida ingestão sem mastigação com vistas à aquisição de um corpo considerado ideal.

A busca de qualidade e preço dos produtos, assim como a segurança quanto ao produto foram motivos determinantes para a manipulação dos suplementos alimentares. Enquanto alguns praticantes alteram apenas em decorrência do custo, outros privilegiam a qualidade do produto, independentemente do preço. A relação entre a qualidade e o valor do produto parece não se vincular à orientação profissional, mas ao poder aquisitivo dos participantes. Quanto à segurança, fatores como o alcance dos objetivos propostos e a falta de efeitos colaterais são dois dos elementos centrais para a manutenção dos produtos usados.

Nota-se como algumas categorias temáticas, relativas aos motivos de alterar ou manter os produtos, se assemelham aos critérios para optar por determinado suplemento alimentar, como pode ser visualizado nos Quadros 1 e 2. Por exemplo, a "segurança quanto ao produto" relacionada à manutenção ou alteração dos produtos. É possível relacioná-la à categoria temática "riscos evitados", vinculada à escolha do suplemento alimentar. Não ter efeito colateral, conhecer os resultados ou mesmo atingir os objetivos desejados é uma forma de evitar riscos e danos. Igualmente, a importância da "orientação profissional" reforça a ideia da "eficácia científica". Isto demonstra a tentativa de superar o senso comum e a busca pela aquisição de uma racionalidade científica, capaz de respaldar as escolhas dos pesquisados.

Entretanto há certas diferenças: enquanto para a escolha dos produtos parece haver um equilíbrio entre o preço e a qualidade, para a manutenção ou alteração do produto, o que mais importa é a qualidade, conforme pode ser visto comparativamente entre os Quadros 1 e 2. Essa realidade sobre a qualidade pode ser expressa na segurança alimentar que se coaduna com a atual preocupação da comunidade científica e governamental, embora, de acordo com Silva e Ferreira (2014), parte dos fabricantes ainda esteja comercializando produtos em 
Rev. Interd. em Cult. e Soc. (RICS), São Luís, v. 7, n. 1, p. 148 - 168, jan./jun. 2021

ISSN eletrônico: 2447-6498

situação irregular. Por vezes, os produtos atendem a legislação vigente, no entanto os teores das substâncias podem não corresponder ao rótulo (LOVATO et al., 2014).

\subsection{Aprendendo sobre os produtos...}

Quadro 3 - Fontes de informação sobre os produtos

\begin{tabular}{|c|c|}
\hline $\begin{array}{l}\text { Fontes de informação } \\
\text { sobre os produtos }\end{array}$ & Exemplos de respostas \\
\hline $\begin{array}{c}\text { Profissionais } \\
\text { (nutricionista; professor } \\
\text { de Educação Física) }\end{array}$ & $\begin{array}{l}\text { - Com a minha nutricionista. } \\
\text { - Leio bastante e também com a nutricionista. } \\
\text { - Sigo a indicação da nutricionista. } \\
\text { - Com a minha "nutri". } \\
\text { - Sempre com profissional de Educação Física. } \\
\text { - Geralmente com o professor da academia e na } \\
\text { internet. } \\
\text { - Com meu personal. }\end{array}$ \\
\hline $\begin{array}{c}\text { Artigos científicos e } \\
\text { informações legais ou de } \\
\text { cunho biomédico }\end{array}$ & $\begin{array}{l}\text { - Pesquiso na internet, preferencialmente em fontes } \\
\text { com embasamento científico; procuro informação } \\
\text { com profissionais da área para esclarecer dúvidas. } \\
\text { - Entidades normativas internacionais. } \\
\text { - Base de dados Scielo, artigos adicionais e } \\
\text { consumidores que realizaram laudos verificando a } \\
\text { quantidade proteica por produto. } \\
\text { - Sites especializados, seja de cunho científico ou } \\
\text { apenas de praticantes consagrados pela história dos } \\
\text { esportes de força; periódicos científicos; revistas de } \\
\text { conteúdo científico especializado; sites, em geral, que } \\
\text { sejam consagrados como de qualidade confiável; } \\
\text { postagens em redes sociais de profissionais } \\
\text { consagrados, do Brasil e internacionais, da área de } \\
\text { saúde, sobre o tema. }\end{array}$ \\
\hline Internet & $\begin{array}{l}\text { - } \quad \text { Em vários sites e fóruns de amigos. } \\
\text { - } \quad \text { Sites de nutrição, site da Anvisa e afins. } \\
\text { - } \quad \text { Na internet, material de profissional conceituado. }\end{array}$ \\
\hline $\begin{array}{c}\text { Amigos, parentes e outros } \\
\text { Alunos }\end{array}$ & $\begin{array}{l}\text { - Apenas leituras na internet conversas na academia. } \\
\text { - Na internet e junto a outros consumidores. } \\
\text { - Me baseio em relatos de usuários e pesquisas na } \\
\text { internet. }\end{array}$ \\
\hline
\end{tabular}

Fonte: Dados originais da pesquisa

O Quadro 3 indica como os praticantes aprendem sobre os produtos e quais fontes de informação costumam consultar para consumir determinado suplemento alimentar. Quando se busca as fontes de informação sobre os produtos, detectou-se mais uma vez a participação dos profissionais, sejam nutricionistas ou profissionais de Educação Física, como fontes de informação privilegiadas. No entanto, ressalta-se que, para a "escolha" ou "manipulação" 
Rev. Interd. em Cult. e Soc. (RICS), São Luís, v. 7, n. 1, p. 148 - 168, jan./jun. 2021 ISSN eletrônico: 2447-6498

desses produtos (Quadros 1 e 2), não há tantas menções específicas ao profissional de Educação Física. Quando os sujeitos se referem como “aprendem" sobre os suplementos alimentares, o professor emerge como um agente principal de fontes de informação.

Comparando esses dados com o estudo de Hirschbruch; Fisberg e Mochizuki (2008), sobre o uso de suplementos alimentares por jovens frequentadores de academias em São Paulo, identificou-se uma diferença. Em vez de nutricionistas serem responsáveis pela indicação de informações sobre os suplementos alimentares, o que prevaleceu foram as indicações de treinadores ou de personal trainers (HIRSCHBRUCH; FISBERG; MOCHIZUKI, 2008). De certo modo, argumenta-se que os participantes aqui analisados têm a possibilidade de acionar e consumir atendimentos nutricionais e não somente a "orientação" que recebe do profissional de Educação Física presente na sala de musculação.

Outra fonte de informação identificada neste estudo foi o uso de artigos científicos. Alguns praticantes buscam informações legais ou de cunho biomédico com o intuito de se esclarecer sobre o teor dos produtos. Características ou composições nutricionais dos produtos e seus potenciais efeitos também parecem fazer parte desse interesse. O consumo desse tipo de leitura pode se associar ao perfil de grande parte dos pesquisados com ensino superior, o que pode ampliar mais uma opção de fonte, embora não se descarte a busca desse material por outros grupos sociais. Neste ponto, o conhecimento científico é identificado como um "saber verdadeiro" que qualifica as informações e tira dúvidas, lembrando que os saberes biomédicos centram-se no corpo biológico (LE BRETON, 2011). Ainda que pesem os aspectos técnicos, Le Breton (2016) lembra que o corpo encarna uma contínua "falsa evidência".

A internet em suas variadas possibilidades também tem sido fonte de informação, o que pode contribuir para a autoprescrição. Os avanços tecnológicos dos dispositivos móveis e e da comunicação online, associados à popularidade das redes sociais permeadas de imagens, vídeos e textos, parecem assumir cada vez mais um espaço de informações para os potenciais consumidores desses tipos de produto. Nesse contexto, deve-se considerar que os próprios sites de compra e venda de suplementos alimentares munem-se da espetacularização de propagandas que costumam expor corpos ditos ou considerados "bonitos", "belos", "sarados", "malhados" ou "bombados" (BOMBARDA; ROCHA, 2020). Assim, a internet caracteriza-se por um espaço privilegiado de anúncios que prometem corpos " $f i t$ " em curto período de tempo com o uso desses produtos. Criam-se, portanto, imaginários sociais sobre ser "fit" atrelados a uma mercadoria de fácil consumo e acesso como as cápsulas, géis, tabletes, pós ou líquidos que permitiriam o destaque de si perante os outros frequentadores da academia. 
Rev. Interd. em Cult. e Soc. (RICS), São Luís, v. 7, n. 1, p. 148 - 168, jan./jun. 2021 ISSN eletrônico: 2447-6498

Debates em fóruns e grupos em redes sociais já foram palco de análises, como o trabalho de Machado e Fraga (2017) que detectou como os sujeitos interagem virtualmente com o intuito de entenderem os usos de anabolizantes. Nesses tipos de ambientes virtuais, Stolarski et al. (2018) identificaram também como os suplementos alimentares são amplamente comercializados, bem como notaram o potencial de circulação dos profissionais de saúde, o que denota cada vez mais a necessidade de investigações no campo da internet.

Outras fontes de informação são amigos, parentes e outros consumidores de suplementos alimentares. Tanto a autoprescrição como a influência de amigos são consideradas comuns (HIRSCHBRUCH; FISBERG; MOCHIZUKI, 2008) e, atualmente, as redes sociais se tornaram um universo de compartilhamento de dados e interações acerca de vários produtos. Ademais, treinadores, nutricionistas, professores de Educação Física e amigos também aparecem em outros estudos (NABUCO et al., 2017).

Pode-se considerar ainda, neste contexto das relações com os amigos, parentes e outros consumidores, as interações estabelecidas entre os diversos grupos sociais. Ressalta-se como esse consumo de suplementos alimentares está vinculado às dimensões da vida social uma vez que: "Mais que alimentar-se conforme o meio a que pertence, o homem se alimenta de acordo com a sociedade a que pertence e, ainda mais precisamente, ao grupo, estabelecendo distinções e marcando fronteiras precisas" (MACIEL, 2001, p. 149).

Assim, finaliza-se demonstrando que todo o processo de escolha dos produtos entre os frequentadores de academias, em dada medida, segue o processo de seleção de outros alimentos e nutrientes. Por mais que apresentem aspectos importantes do ponto de vista biológico, segurança e evidências científicas, há influências de amigos e parentes. Destarte, é importante a informação dada pelos grupos, como uma forma de pertencimento a eles.

O processo alimentar precisa ser desnaturalizado, pois os aspectos biológicos estão entrelaçados aos culturais, o que já era afirmado por Mauss (2003) em relação às técnicas corporais, ou seja, sobre os modos como os corpos vão sendo usados de acordo com cada sociedade. Assim, nesta pesquisa, as aprendizagens sobre as substâncias são influenciadas pelo coletivo indo ao encontro de Mauss (2003), quando destaca que, ao vivermos, somos capazes de aprender, pela imitação, pela moda ou pelo prestígio daquele que nos ensina. Desse modo, emerge um processo de "aculturação do tomar" suplementos alimentares que se reconfigura a todo instante em um movimento de socialização entre aqueles sujeitos que usam esses produtos dentro e fora das academias.

\section{CONSIDERAÇÕES FINAIS}


Rev. Interd. em Cult. e Soc. (RICS), São Luís, v. 7, n. 1, p. 148 - 168, jan./jun. 2021 ISSN eletrônico: 2447-6498

Foi possível detectar como os consumidores de suplementos alimentares gerenciam essas substâncias ao longo do tempo, mais precisamente como as escolhem e manipulam. Além disso, avançou-se na compreensão de como aprendem sobre os produtos. Em outras palavras, o processo de se tornar um "usuário" de suplementos alimentares se estabelece desde como optar pelo produto, passando pelo aprendizado de como manejar essas substâncias, até quando se tornam "especialistas" de como ingeri-los. É interessante destacar, diante desses resultados, que não é somente os homens que utilizam tais substâncias, pois as mulheres também fazem uso desses produtos. Além disso, os consumidores não são apenas aqueles que possuem renda salarial mais alta, pelo contrário, o uso de suplementos também abarca consumidores que possuem faixas salariais menores, o que influencia na escolha dos produtos.

Assim, os motivos para a escolha dos produtos estão relacionados à marca, à relação custo-benefício, aos riscos que podem ser evitados e também à eficácia científica. Já os motivos de alterações ou manutenções de determinados suplementos alimentares se referem ao tipo de orientação profissional, às experiências negativas e às novidades no mercado ou no próprio treino, além da busca de qualidade e preço das substâncias, bem como da segurança que o produto repassa. No tocante às fontes de informação sobre os suplementos alimentares, destacam-se os profissionais, os artigos científicos, a internet e até mesmo a influência de amigos, parentes e usuários dos produtos.

Ressalta-se que o ato de ingerir suplementos alimentares não se caracteriza por um comportamento individual, mas também uma construção social e cultural, fato demonstrado como sendo muito presente na cidade do Rio de Janeiro. Assim, tais agenciamentos do corpo diante desses produtos nos fornecem indícios de como os aspectos relacionais e coletivos estão presentes na cultura fitness. Em outras palavras, "tomar para treinar" relaciona-se ao "tomar para viver", pois os suplementos alimentares permitem que os usuários não somente tenham lucros sociais dentro da academia, como também nas esferas da vida social.

De acordo com esta pesquisa, ainda há uma carência de trabalhos que investiguem as peculiaridades e os diversos motivos e critérios em alterarem ou não o consumo de determinados suplementos alimentares a partir da ótica sociocultural. Além disso, grande parte dos trabalhos não aprofunda efetivamente como os usuários de suplementos alimentares mais privilegiam os produtos, no que se baseiam, com quem ou onde formam seus pontos de vista a respeito da manipulação das substâncias. Ademais, essas pesquisas tangenciam as considerações sobre a ocorrência de hierarquias e lógicas de escolha de determinados suplementos alimentares e como costumam se manter informados em relação ao seu consumo. 
Rev. Interd. em Cult. e Soc. (RICS), São Luís, v. 7, n. 1, p. 148 - 168, jan./jun. 2021 ISSN eletrônico: 2447-6498

Este trabalho pode abrir inúmeras frentes de investigação. Futuramente, pode-se explorar como as mídias e tecnologias digitais ou as ferramentas de marketing impactam não somente no consumo de suplementos alimentares, como também de que maneiras atraem os públicos para os seus "corpos” em diferentes espaços fitness. Pesquisas que aprofundem os pontos de vista de não-usuários desses produtos dos mesmos espaços de práticas corporais também seriam importantes para compreender os usos de suplementos alimentares objetivando o rendimento atlético ou, até mesmo, para vida pessoal e/ou profissional.

Logo, em que pesem as limitações metodológicas da presente pesquisa, especialmente, no que diz respeito ao seleto universo empírico no lócus aqui analisado, recomendam-se cada vez mais empreendimentos investigativos qualitativos pela perspectiva sociocultural que atentem para essas questões e que incluam em suas análises informações interseccionais sobre gênero e raça/cor/etnia. Ademais, o presente trabalho recomenda que outros estudos tragam à tona a realidade vivida e experienciada dos usuários de suplementos alimentares a fim de aproximar a produção de saberes acadêmicos com a aplicabilidade desses dados em diferentes espaços de práticas corporais, sobretudo para além do universo das academias de ginástica.

\section{REFERÊNCIAS}

ABE-MATSUMOTO, Lucile Tiemi; SAMPAIO, Geni Rodrigues; BASTOS, Deborah H. M. Suplementos vitamínicos e/ou minerais: regulamentação, consumo e implicações à saúde.

Cadernos de Saúde Pública, Rio de Janeiro, v. 31, n. 7, p. 1371-1380, 2015.

APPADURAI, Arjun. How to make a national cuisine: cookbooks in contemporary India. Comparative Studies in Society and History, Cambridge, v. 30, n. 1, p.3-24, 1988.

BAUDRILLARD, Jean. A sociedade de consumo. Lisboa: Edições 70, 2011.

BOLTANSKI, Luc. As classes sociais e o corpo. 3. ed. São Paulo: Paz e Terra, 2004.

BOMBARDA, Fábio; ROCHA, Damião. A espetacularização dos corpos whein protein: as propagandas de suplementos e o fenômeno de objetificação. Educação, Escola e Sociedade, Montes Claros, v. 13, e202003, 2020.

BOURDIEU, Pierre. O poder simbólico. 4. ed. Rio de Janeiro: Bertrande Brasil, 2001.

BRASIL. Agência Nacional de Vigilância Sanitária. Suplementos alimentares. Disponível em: http://portal.anvisa.gov.br/suplementos-alimentares. Acesso em: 18 jul. 2019.

CASTANHO, Gabriela Kaiser Fullin; FONTES, Eduardo Bodnariuc; FERNANDES, Paula Teixeira. O perigo da contaminação de suplementos alimentares com substâncias ilícitas para 
Rev. Interd. em Cult. e Soc. (RICS), São Luís, v. 7, n. 1, p. 148 - 168, jan./jun. 2021 ISSN eletrônico: 2447-6498

os praticantes de exercício físico e esporte. Conexões: Educação Física, Esporte e Saúde, Campinas, v. 12, n. 1, p. 161-180, 2014.

CASTIEL, Luis David; FERREIRA, Marcos Santos; MORAES, Danielle Ribeiro. Os riscos e a promoção do autocontrole na saúde alimentar: moralismo, biopolítica e crítica parresiasta. Ciência \& Saúde Coletiva, Rio de Janeiro, v. 19, n. 5, p. 1523-1532, 2014.

CASTRO, Ana Lucia. Culto ao corpo e sociedade: mídia, estilos de vida e cultura de consumo. 2. ed. São Paulo: Annablume/ FAPESP, 2007.

CASTRO, Helisa Canfield; MACIEL, Maria Eunice. A comida boa para pensar: sobre práticas, gostos e sistemas alimentares a partir de um olhar socioantropológico. Demetra: Alimentação, Nutrição \& Saúde, Rio de Janeiro, s. 1, v. 8, p. 321-328, 2013.

COLLAÇO, Janine; MENASCHE, Renata. Comer contemporâneo: e não é que comida continua boa para pensar? Sociedade e Cultura, Goiânia, v. 18, n. 1, p. 5-11, 2015.

CORREIA, Camila; GOMES, Ivan. Principais cuidados e investimentos corporais de frequentadoras de uma academia para mulheres de Vitória/ES. Motrivivência, Florianópolis, v. 30, n. 53, p. 18-34, 2018.

GARBIN, Helena Beatriz da Rocha; GUILAM, Maria Cristina Rodrigues; PEREIRA NETO, André Faria. Internet na promoção da saúde: um instrumento para o desenvolvimento de habilidades pessoais e sociais. Physis: Revista de Saúde Coletiva, Rio de Janeiro, v. 22, n. 1, p. 347-363, 2012.

GOLDENBERG, Mirian. A arte de pesquisar: como fazer pesquisa qualitativa em ciências sociais. 12. ed. Rio de Janeiro, Record, 2011.

HELMAN, Cecil. Cultura, saúde e doença. 2. ed. Porto Alegre: Artes Médicas, 1994.

HIRSCHBRUCH, Marcia Daskal; FISBERG, Mauro; MOCHIZUKI, Luis. Consumo de suplementos por jovens frequentadores de academias de ginástica em São Paulo. Revista Brasileira de Medicina do Esporte, São Paulo, v. 14, n. 6, p. 539-543, 2008.

JUZWIAK, Claudia Ridel. Reflection on sports nutrition: where we come from, where we are, and where we are headed. Revista de Nutrição, Campinas, v. 29, n. 3, p. 435-444, 2016.

KERKSICK, Chad et al. ISSN exercise \& sports nutrition review update: research \& recommendations. Journal of the International Society of Sports Nutrition, Woodland Park, v. 15, n. 1, p. 1-57, 2018.

KLOTZ-SILVA, Juliana; PRADO, Shirley Donizete; SEIXAS, Cristiane Marques. A força do "hábito alimentar": referências conceituais para o campo da Alimentação e Nutrição. Physis:

Revista de Saúde Coletiva, v. 27, n. 4, p. 1065-1085, 2017.

KUWAE, Christiane Ayumi et al. Concepções de alimentação saudável entre idosos na Universidade Aberta da Terceira Idade da UERJ: normas nutricionais, normas do corpo e normas do cotidiano. Revista Brasileira de Geriatria e Gerontologia, Rio de Janeiro, v. 18, n. 3, p. 621-630, 2015. 
Rev. Interd. em Cult. e Soc. (RICS), São Luís, v. 7, n. 1, p. 148 - 168, jan./jun. 2021 ISSN eletrônico: 2447-6498

LE BRETON, David. Antropologia do corpo e modernidade. Petrópolis: Vozes, 2011.

LE BRETON, David. Condutas de risco: dos jogos de morte ao jogo de viver. Campinas: Autores Associados, 2009.

LE BRETON, David. L’adieu au corps. Paris: Métailié, 1999.

LE BRETON, David. La sociologie du corps. Paris: PUF, 2016.

LEWIS, Kevin et al. Tastes, ties, and time: a new social network dataset using Facebook.com. Social Networks, Manchester, v. 30, n. 4, p. 330-342, 2008.

LOVATO, Frederico et al. Avaliação da conformidade de suplementos alimentares frente à legislação vigente. Revista Brasileira de Nutrição Esportiva, v. 8, n. 47, p. 330-335, 2014.

LÜDORF, Sílvia Maria Agatti. Metodologia da pesquisa: do projeto ao trabalho de conclusão de curso. Curitiba: Appris, 2017.

MACHADO, Eduardo Pinto; FRAGA, Alex Branco. Ratos de academia on-line: debates sobre musculação em um fórum virtual. Revista Brasileira de Ciência e Movimento, Brasília, v. 25, n. 1, p. 141-150, 2017.

MACIEL, Maria Eunice. Cultura e alimentação ou o que têm a ver os macaquinhos de Koshima com Brillat-Savarin? Horizontes Antropológicos, Porto Alegre, v. 7, n. 16, p. 145$156,2001$.

MALYSSE, Stéphane. Em busca dos (h)alteres-ego: olhares franceses nos bastidores da corpolatria carioca. In: GOLDENBERG, Mirian (Org.). Nu \& Vestido: dez antropólogos revelam a cultura do corpo carioca. 2. ed. Rio de Janeiro: Record, 2007. p. 79-137.

MAUGHAN, Ronald et al. IOC consensus statement: dietary supplements and the highperformance athlete. British Journal of Sports Medicine, London, v. 52, p. 439-455, 2018.

MAUSS, Marcel. Sociologia e Antropologia. São Paulo: Cosac Naify, 2003.

MINTZ, Sidney Wilfred. Comida e antropologia: uma breve revisão. Revista Brasileira de Ciências Sociais, São Paulo, v. 16, n. 47, p. 31-41, 2001.

MOREIRA, Fernanda Pedrotti; RODRIGUES, Kelly Lameiro. Conhecimento nutricional e suplementação alimentar por praticantes de exercícios físicos. Revista Brasileira de Medicina do Esporte, São Paulo, v. 20, n. 5, p. 370-373, 2014.

NABUCO, Hellen Clair Garcez et al. Use of dietary supplements among brazilian athletes. Revista de Nutrição, Campinas, v. 30, n. 2, p. 163-173, 2017.

PARRA, Renata Marques Toews; PALMA, Alexandre; PIERUCCI, Anna Paola Trindade Rocha. Contaminação de suplementos dietéticos usados para prática esportiva: uma revisão de literatura. Revista Brasileira de Ciências do Esporte, Porto Alegre, v. 33, n. 4, p. 10711084, 2011. 
Rev. Interd. em Cult. e Soc. (RICS), São Luís, v. 7, n. 1, p. 148 - 168, jan./jun. 2021 ISSN eletrônico: 2447-6498

SABINO, César; LUZ, Madel T.; CARVALHO, Maria Cláudia. O fim da comida: suplementação alimentar e alimentação entre frequentadores assíduos de academias de musculação e fitness do Rio de Janeiro. História, Ciências, Saúde - Manguinhos, Rio de Janeiro, v. 17, n. 2, p. 343-356, 2010.

SAUERBRONN, João Felipe Rammelt; TONINI, Karla Andrea Dulce; LODI, Marluce Dantas de Freitas. Um estudo sobre os significados de consumo associados ao corpo feminino em peças publicitárias de suplementos alimentares. REAd. Revista Eletrônica de Administração, Porto Alegre, v. 17, n. 1, p. 1-25, 2011.

SEGATA, Jean; RIFIOTIS, Theophilos (Orgs.). Políticas etnográficas no campo da cibercultura. Brasília: ABA publicações, 2016.

SHILLING, Chris. Sociology and the body: classical traditions and new agendas. The Sociological Review, London, v. 55, p. 2-18, 2007.

SILVA, Alan Camargo. Corpos no limite: suplementos alimentares e anabolizantes em academias de ginástica. Jundiaí: Paco Editorial, 2017.

SILVA, Alan Camargo; FERREIRA, Jaqueline. "Suando a camisa" em academias de ginástica do Rio de Janeiro: um estudo etnográfico. Physis: Revista de Saúde Coletiva, Rio de Janeiro, v. 26, n. 3, p. 769-783, 2016.

SILVA, Alan Camargo; FREITAS, Diego Costa; LÜDORF, Sílvia Maria Agatti. Profissionais de Educação Física de academias de ginástica do Rio de Janeiro e a pluralidade de concepções de corpo. Revista Brasileira de Ciências do Esporte, Porto Alegre, v. 41, n. 1, p. 102-108, 2019.

SOUZA, Ricardo Pires et al. Conflitos de interesses na pesquisa médico-farmacológica. Revista Bioética, Brasília, v. 21, n. 2, p. 237-240, 2013.

STARR, Ranjani. Should states and local governments regulate dietary supplements? Drug Testing and Analysis, Cologne, v. 8, n. 3-4, p. 402-406, 2016.

STOLARSKI, Graciele et al. Blogueiros fitness no Instagram: o corpo e o merchandising editorial de suplementos alimentares. Revista Eletrônica de Comunicação, Informação e Inovação em Saúde, Rio de Janeiro, v. 12, n. 4, p. 1-21, 2018.

THOMAS, Travis; ERDMAN, Kelly Anne; BURKE, Louise. American College of Sports Medicine Joint Position Statement. Nutrition and Athletic Performance. Medicine \& Science in Sports \& Exercise, Madison, v. 48, n. 3, p. 543-568, 2016.

TURATO, Egberto Ribeiro. Tratado da metodologia da pesquisa clínico-qualitativa: construção teórico-epistemológica, discussão comparada e aplicação nas áreas da saúde e humanas. 5. ed. Petrópolis: Vozes, 2011.

VARANDA, Sarai Schmidt; BENITES, Larissa Cerignoni; SOUZA NETO, Samuel. O processo de validação de instrumentos em uma pesquisa qualitativa em Educação Física. Motrivivência, Florianópolis, v. 31, n. 57, p. 1-15, 2019. 
Rev. Interd. em Cult. e Soc. (RICS), São Luís, v. 7, n. 1, p. 148 - 168, jan./jun. 2021 ISSN eletrônico: 2447-6498

VASCONCELLOS-SILVA, Paulo Roberto et al. As novas tecnologias da informação e o consumismo em saúde. Cadernos de Saúde Pública, Rio de Janeiro, v. 26, n. 8, p. 1473$1482,2010$.

VENTURINI, Ivana Vedoin et al. Musas fitness e a tríade corpo-consumo-felicidade. Movimento, Porto Alegre, v. 26, e26003, 2020. 